\title{
Optimal Integration of a Hybrid Solar-Battery Power Source into Smart Home Nanogrid with Plug-In Electric Vehicle
}

\author{
Xiaohua $\mathrm{Wu}^{\mathrm{a}}$, Xiaosong $\mathrm{Hu}^{\mathrm{b}, \mathrm{c}, * *}$, Yanqiong Teng ${ }^{\mathrm{a}}$, Shide Qian ${ }^{\mathrm{d}}$, Rui Cheng ${ }^{\mathrm{a}}$ \\ ${ }^{a}$ School of Automobile and Transportation, Xihua University, Chengdu, 610039, China \\ ${ }^{b}$ State Key Laboratory of Mechanical Transmissions, Department of Automotive \\ Engineering, Chongqing University, Chongqing, 400044, China \\ ${ }^{c}$ Advanced Vehicle Engineering Centre, Cranfield University, Cranfield, MK43 OAL, UK \\ ${ }^{d}$ Beijing Benz Automotive Co.Ltd, Beijing 100176, China
}

\begin{abstract}
Hybrid solar-battery power source is essential in the nexus of plug-in electric vehicle (PEV), renewables, and smart building. This paper devises an optimization framework for efficient energy management and components sizing of a single smart home with home battery, PEV, and potovoltatic (PV) arrays. We seek to maximize the home economy, while satisfying home power demand and PEV driving. Based on the structure and system models of the smart home nanogrid, a convex programming $(\mathrm{CP})$ problem is formulated to rapidly and efficiently optimize both the control decision and parameters of the home battery energy storage system (BESS). Considering different time horizons of optimization, home BESS prices, types and control modes of PEVs, the parameters of home BESS and electric cost are systematically investigated. Based on the developed $\mathrm{CP}$ control law in home to vehicle $(\mathrm{H} 2 \mathrm{~V})$ mode and vehicle to home (V2H) mode, the home with BESS does not buy electric energy from the grid during the electric price's peak periods.
\end{abstract}

*This work was supported in part by Science and Technology Department of Sichuan Province (Grant Nos. 2017TD0026, 2016HH0010, 2016GZ0027, and 2015TD0021), NSF of China (Grant No. 51375402), Education Department of Sichuan Province (Grant No. 201610623061), and the Fundamental Research Funds for the Central Universities (Project No. 0903005203398).

${ }^{* *}$ Corresponding author (X.Wu and $\mathrm{X}$. Hu equally contributed to this research work.)

Email address: xiaosonghu@iee. org (Xiaosong $\mathrm{Hu}$ )

Preprint submitted to Journal of Power Sources

July 12, 2017

Published by Elsevier. This is the Author Accepted Manuscript issued with:

Creative Commons Attribution Non-Commercial No Derivatives License (CC:BY:NC:ND 4.0).

The final published version (version of record) is available online at DOI:10.1016/j.jpowsour.2017.07.086

Please refer to any applicable publisher terms of use. 
Keywords: Home Battery, Plug-In Electric Vehicle, Solar Energy, Energy

Management, Optimization, Smart Home

\section{Introduction}

\subsection{Motivation}

The present energy demand and environmental crisis has been promoting the rapid development of electric vehicles $(\mathrm{EVs})$ and renewables [1, 2]. However, EVs charging activities and some renewable energy generation, such as solar and wind power, are always intermittent and volatile. Reconciling EVs and renewables to ensure optimal usage of electric power is critical for the performance and economy of smart grid [3, 4], especially when larger-scale distributed generation (DG) units and EVs are deployed [5]. As a consequence, researchers have recently focused on developing effective management and sizing techniques for integrating EVs and renewables into house loads and the grid. New material and structure of renewables devices were also reported. For example,a newly designed microfluidic architecture with a hyperflexible siliconic matrix is proposed in [6], as a polymeric cage in dye-sensitized solar cell (DSSC). A photocurable polymeric membrane is employed as quasi-solid electrolyte for both the electrochromic device and the DSSC in [7. Moreover, a flexible integrated energy harvesting and storage system is devised in [8] by coupling DSSC and an electrical double layer supercapacitor.

Related to the recent attention given to smart grid vision, smart home nanogrids that can optimize energy consumption and lower electricity bills have also gained particular importance. The results in [9] have comprehensively demonstrated the second-life battery energy storage's performance in solar charging, home load following, and utility demand side management for a single family home. Developing a smart home energy management system (SHEMS) and component sizing method has become a common global priority to support the trend toward a more sustainable energy supply for smart grid. One of the 
key features of smart home nanogrid is the SHEMS that intelligently controls household loads through an association between smart meters, smart appliances, EVs, and home power generation and storage, etc. Besides, power source dimension is another important factor. Hence, this paper focuses on optimal energy management and sizing of a smart home nanogrid with home battery energy storage system (BESS), plug-in electric vehicle (PEV), and potovoltatic (PV) power supply.

\subsection{Literature review}

There is a rich literature for optimized home energy management (HEM) approaches, which can be generally categorized into mixed-integer linear programming (MILP) [10], geometric program [11, model predictive control (MPC) [12, dynamic programming (DP) [13, stochastic dynamic programming (SDP) [14. The optimal operation of a smart household with a PV, a home battery bank, and an EV with vehicle to home (V2H) option is considered through solving a MILP in [15]. A MILP model of the HEM structure is established in [16] to investigate a joint evaluation of a dynamic pricing and peak power limiting based demand response (DR) strategy, with a bi-directional utilization of EV and energy storage system. An optimal day-ahead household appliances scheduling is developed in [17. under hourly pricing and peak power-limiting based DR strategies, where thermostatically and non-thermostatically controllable loads are explicitly modeled using MILP. In addition, the optimal operation of a smart neighborhood, in terms of minimizing the total energy procurement cost, is analyzed using MILP by considering all possible bi-directional power flows in [18. A MILP model of home energy management system (HEMS), as well as a wavelet transform (WT)-artificial neural network (ANN) forecasting of residential loads, is described in [19] for different price signals. A MILP-based DR strategy with end-user comfort violation minimization is synthesized for residential heating, ventilation, and air conditioning (HVAC) units in [20. Considering DR, sizing of PV and energy storage system applied in smart households is assessed with HEM modeling in a MILP framework in [21]. It is clear that MILP 
has been widely adopted for either creating efficient operational schedules for HEM or sizing of component. However, few studies exploring HEM MILP models considered optimal component size and control strategy simultaneously. A new effective tool, convex programming (CP), which can rapidly and efficiently optimize both management strategy and parameters, has also been applied by some researchers in the energy management field.

Due to the significant advantage of $\mathrm{CP}$ in computational efficiency, $\mathrm{CP}$ is gaining growing popularity in energy management of energy systems. The problem of integrating residential PV power generation and storage systems into the smart grid is addressed in 22] for simultaneous peak power shaving and total electricity cost minimization over a billing period, where a convex optimization problem is formulated and solved. A renewable energy buying-back scheme with dynamic pricing to achieve the goal of energy efficiency for smart grids is modeled as a convex problem in 23, which can significantly reduce peak time loading and efficiently balance system energy distribution. Based on convex objectives and constraints of a grid-tied PV storage system, an optimization problem to obtain a control schedule for storage units is solved by CVX in [24]. Based on the objective of reduction of the substation transformer losses, cost saving of energy delivered from the grid, and reduction of the impact on the life-cycle cost of the BESS, a convex optimization approach to schedule charging and discharging of the lithium-ion-based BESS in a distribution feeder with penetration of renewables is discussed in [25]. To assess optimal residential DR in a distribution network, a $\mathrm{CP}$ problem is formulated to minimize electricity payment and waiting time under real-time pricing for a multiagent system in [26]. A novel convex quadratic objective function for active power management of plug-in hybrid electric vehicles (PHEVs) is proposed in 27] for minimizing energy loss of microgrid, where the convexity of the proposed method leads to a fast, precise solution facilitating real-time dispatch. Given the price information, a versatile CP framework for the load management of various household appliances, in order to support DR through energy management system (EMS) in a single smart home, is constructed in [28]. To perform effective storage 
control based on the predictions of PV power generation and load power consumption, 29] splits a residential storage control algorithm into two tiers: the global control tier and the local control tier. The global tier, which is performed to globally plan future discharging/charging schemes of the storage system, is formulated and solved by convex optimization at each decision epoch. It is also mentioned in [29] that finding the optimal sizes of the PV module and storage module with a given budget is possible, but not elaborated.

A number of efforts has probed energy management of smart grid with renewables. Few studies, however, consider optimal component size and control strategy simultaneously. CP has been successfully applied to simultaneously optimize the component size and energy controller for hybrid vehicles [30, 31, 32, 33. In [31], for example, the optimal sizes of the battery pack and fuel cell system, as well as power management strategy, are optimally determined by CP. In this paper, CP is, for the first time, extended to rapidly and efficiently optimize both HEM strategy and sizes of home BESS of a single smart home with both PEV and PV arrays.

\subsection{Contributions}

To overcome the downsides of the previous studies, this paper delivers three key contributions to the literature. First, CP is leveraged to rapidly and efficiently optimize both the control decision and parameters of the home BESS in the smart home with PEV and PV arrays. To the best knowledge of the authors, this is the first study on the CP-driven joint optimization of control strategy and component size of the home BESS with the participation of PEV and PV arrays. Second, based on different time horizons of optimization, home BESS prices, types and control modes of PEV, we attain the optimal parameters of the home BESS and electric cost. In contrast to the total electric cost of a home without home BESS, the usefulness of home battery energy storage to increse the home economy is systematically evaluated. Finally, using the CP control law in home to vehicle $(\mathrm{H} 2 \mathrm{~V})$ mode and vehicle to home (V2H) mode demonstrates that the home with BESS does not buy electric energy from the 
grid during the peak periods of electric tariff.

\subsection{Outline of paper}

The remainder of the paper proceeds as follows. Section 2 details the system structure and models of the smart home nanogrid. The CP problem is formalized in Section 3. The optimization results are discussed in Section 4, followed by conclusions summarized in Section 5 .

\section{Structure and models}

\subsection{Smart home nanogrid structure}

We consider a single smart home as shown in Fig. 1 34, including a PEV battery, solar panels, a home BESS, home equipments, the utility grid, and a SHEMS. The SHEMS communicates with home battery management system (BMS), home appliances, the PEV BMS, and solar panels. The PEV battery is designed to allow both bidirectional and unidirectional power flow. The home battery is designed to allow bidirectional power flow. The SHEMS is also utilized to manage the power flow among the PEV battery, home appliances, PV arrays, the home battery, and the utility grid.

\subsection{System model}

The power balance equation of the smart home nanogrid is

$$
\begin{gathered}
P_{\text {grid }, k}=P_{d e m, k}+P_{b, k}+P_{e v c, k} S_{k}-P_{p v, k}, \quad k=0, \ldots, N-1, \\
0 \leq P_{g r i d, k} \leq P_{\text {grid }}^{\max } \\
\qquad S_{k}= \begin{cases}0 & \text { for } t_{d} \leq k \leq t_{a} \\
1 & \text { otherwise, }\end{cases}
\end{gathered}
$$

where we assume $P_{\text {grid, } k} \geq 0$, which means that the house is not permitted to supply power to the grid [12]. Variable $S_{k}$ denotes the PEV state at time $k$, i.e., 


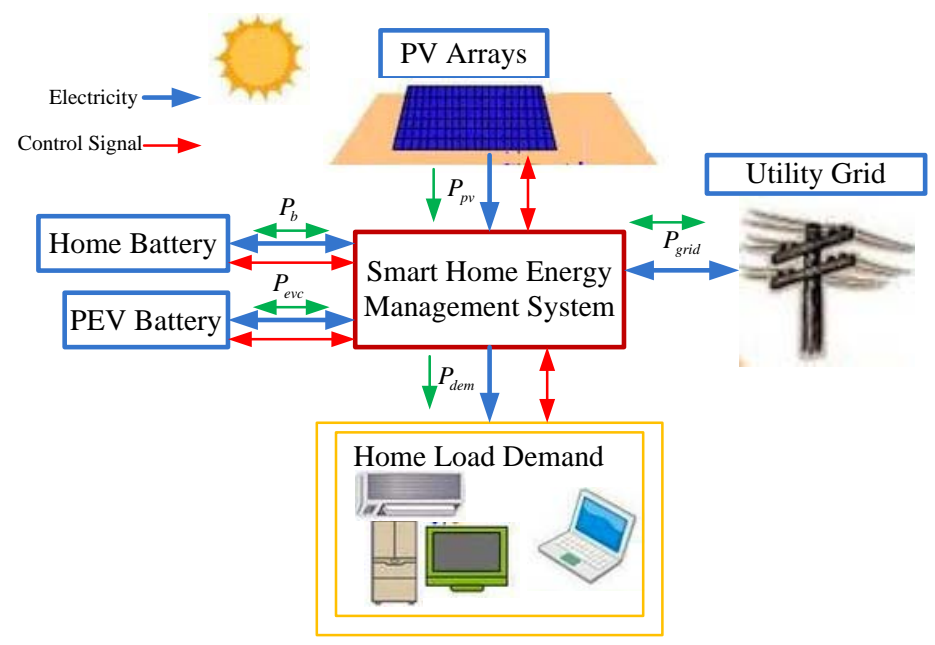

Figure 1: Structure of smart home nanogrid with a PEV and PV arrays [34.

${ }_{137}$ plugged-in $\left(S_{k}=1\right)$ or plugged-out $\left(S_{k}=0\right)$ 34, 35]. In this work, we assume 138 that the PEV plugs-out and plugs-in once a day.

The controller also must maintain PEV battery energy and power within simple bounds 36. The dynamics and constraints of the PEV battery are given by

$$
\begin{array}{r}
E_{e v, k+1}=E_{e v, k}+\Delta t\left(P_{e v c, k}-\eta_{e v c}\left|P_{e v c, k}\right|\right), \quad k=0, \ldots, N-1, \\
E_{e v, 0}=E_{e v, i n i t}, \\
E_{e v}^{p l u g-o u t}=S O C_{e v}^{\max } Q_{e v, e a p}, \\
E_{e v}^{\text {plug-in }}=S O C_{e v}^{\max } Q_{e v, e a p}-E_{d r}, \\
E_{d r}=0.4 Q_{e v c, e a p}, \quad k=0, \ldots, N, \quad k=0, \ldots, N, \quad k=0, \ldots, N-1, \\
Q_{e v c, e a p} S O C_{e v}^{\min } \leq E_{e v, k} \leq Q_{e v c, e a p} S O C_{e v}^{\max }, \quad k \\
P_{e v c}^{\min } \leq P_{e v c, k} \leq P_{e v c}^{\max }, \quad k=0
\end{array}
$$

where we assume $E_{d r}$ is $0.4 Q_{e v c, e a p}$ [37, and the charge power of the PEV battery is positive, by convention.

Likewise, the controller also must maintain home battery energy and power 
within allowable bounds, and its dynamics are depicted by

$$
\begin{array}{r}
E_{b, k+1}=E_{b, k}+\Delta t\left(P_{b, k}-\eta_{b}\left|P_{b, k}\right|\right), \quad k=0, \ldots, N-1, \\
E_{b, 0}=E_{b, \text { init }}, \\
Q_{b, \text { eap }} S O C_{b}^{\min } \leq E_{b, k} \leq Q_{b, \text { eap }} S O C_{b}^{\max }, \quad k=0, \ldots, N, \\
-P_{b}^{\max } \leq P_{b, k} \leq P_{b}^{\max }, \quad k=0, \ldots, N-1,
\end{array}
$$

141

where the charge power is assumed to be positive, by convention.

\section{Optimization problem formulation}

This section presents the CP approach used for solving the optimal parameters design and power management problem for the smart home nanogrid. A standard CP problem is formulated as

$$
\begin{aligned}
\operatorname{minimize} & F(x) \\
\text { s. t. } & f_{i}(x) \leq 0, \quad i=1, \ldots, p, \\
& h_{j}(x)=0, \quad j=1, \ldots, q, \\
& x \in Z
\end{aligned}
$$

where $Z \in R^{n}$ is a convex set, $F(x)$ and $f_{i}(x)$ are convex functions, and $h_{j}(x)$ are affine functions of optimization vector $x$. The theoretical and algorithmic aspects of $\mathrm{CP}$ are detailed in [38]. The convex objective function $F(x)$, which is of great interest to the home owner, is formulated to minimize a summation of the total electric energy cost in the time horizon of optimization and the home BESS cost, for which we mainly consider the battery cost and charger cost:

$$
F=C_{n y}+c_{b} Q_{b, e a p}+c_{c} P_{b}^{\max }
$$

where for simplicity, we assume that the total electric energy cost is the same in every year. As a result, we can deduce $C_{n y}$ as follows:

$$
C_{n y}=n \sum_{k=0}^{N-1} c_{e, k} P_{\text {grid }, k} / 100,
$$


It is easy to see that the objective function $F$ is linear, which is convex. The optimization variables include the state variables $E_{e v, k}$ and $E_{b, k}$, the control variables $P_{e v c, k}$ and $P_{b, k}$, and the optimal design parameters $Q_{b, e a p}$ and $P_{b}^{\max }$. The constraints are the home power balance (1), the PEV battery constraints (4)-(10), the home battery constraints (11)-(14), and the grid limits (2). The inequality constraint functions include Eqns (2), (9), (10), (13), and (14), which are linear and thus convex. The equality constraint functions include Eqns (1), (4)-(8), (11), and (12). Obviously, Eqns (1), (5)-(8), and (12) are linear and affine. However, Eqns (4) and (11) are absolute function, which are not affine. In a standard convex optimization problem, only affine equality constraints are tolerated. The total original problem is not a convex problem, due to the absolute equality constraints, which is essentially nonlinear. However, relaxing (4) and (11) to inequalities gives a convex problem without qualitatively altering the original problem as follows:

$$
\begin{aligned}
E_{e v, k+1} \leq E_{e v, k}+\Delta t\left(P_{e v c, k}-\eta_{e v c}\left|P_{e v c, k}\right|\right), & k=0, \ldots, N-1 . \\
E_{b, k+1} \leq E_{b, k}+\Delta t\left(P_{b, k}-\eta_{b}\left|P_{b, k}\right|\right), & k=0, \ldots, N-1 .
\end{aligned}
$$

Now, Eqn (18) and (19) are absolute inequalities, which are convex, enabling the problem to become a convex problem. A tool, CVX [38, is employed to parse the optimization problem, inducing a semi-definite program that can be efficiently solved by SeDuMi (Self-Dual-Minimization) [39. It should be underlined that thanks to the convexity, a globally optimal solution with arbitrary initialization can be readily accomplished.

\section{Results \& discussion}

\subsection{System parameters}

This section analyses the properties of the proposed CP approach. The key parameters of the smart home are listed in Table 2. All the simulations were run on a PC with a $2.50 \mathrm{GHz}$ Intel Core i5-2450M CPU and $4 \mathrm{~GB}$ of internal memory. Thanks to the mentioned advantages of the proposed method, the CP 
computational time is less than 30 s using CVX tool in the Matlab environment when optimizing component size and control strategy simultaneously. And the CP computational time is less than $1 \mathrm{~s}$ when only optimizing the HEM control strategy with a $24 \mathrm{~h}$ look-ahead horizon.

The hourly home load data and PV power supply data on each day and average from a single family home in California, US [40] are shown in Fig. 2-(a) and (b). The collected data corresponds to date range from 2014-01-01 to 201412-31. The hourly home load demand varies from $0.25 \mathrm{~kW}$ to $4.58 \mathrm{~kW}$. The peak loads always happen from 7:00-15:00 and 18:00-1:00. The hourly PV power supply varies from 0 to $2.81 \mathrm{~kW}$. It is easily observed that the PV power supply is centralized from 9:00 to 15:00 and sometimes more than the instantaneous home load demand. Referring to Pacific Gas and Electric Company's (PG\&E) special EV rate plans for residential customers, they are non-tiered, time-of-use plans as shown in Fig. 2.(c) 41. The electric price is lowest (10 cents/kWh) from 23:00 to 7:00 when the demand is lowest. Electricity is more expensive during Peak (43 cents/kWh, 14:00-21:00) and Partial-Peak (22 cents/kWh, 7:00-14:00 and 21:00 to 23:00) periods. Fig. 2f(d) plots the state of the PEV. The PEV plugs-out from 7:00 to 20:00 (not at home) and plugs-in from 20:00 to 7:00 (at home). It is obvious that the house sells electric energy to the grid with PartialPeak electric price and buys it with peak electric price. If there is a home BESS, users can not only store the redundant PV power, but also buy electric energy with low price for the use of high price time. The home BESS can not only reduce household electric energy costs, but also supply back-up electric energy to the house during lacking of electric power because of blackout.

\subsection{System parameters optimization}

Based on the historical home load demand and PV power generation data, as well as the hourly time-varying electric price and state of PEV, the optimal parameters of home BESS and energy management strategy can be procured via CP. In light of the report of Avicenne Energy, the worldwide battery price might vary from $60 \$ / \mathrm{kWh}$ to $203 \$ / \mathrm{kWh}$ in 2020 42. Considering different 


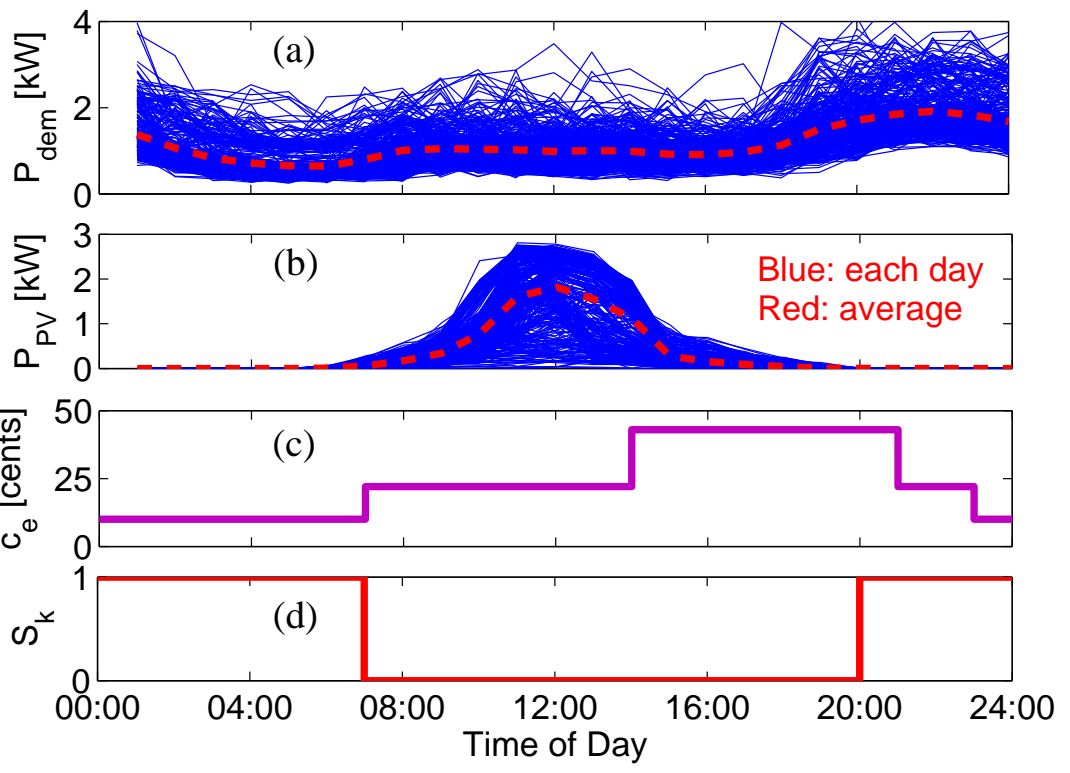

Figure 2: Real-world data of home power demand, PV generation, elelctric price, and state of vehicle.

time horizons of optimization, home BESS prices, different control modes of PEV, the parameters of home BESS can be explored, as well as the total cost. First, we consider that the owner has a Nissan Leaf with $24 \mathrm{kWh}$ battery that cannot discharge power to the home. Independently of the time horizon of optimization (1 to 10$)$, battery price ( $60 \$ / \mathrm{kWh}$ to $203 \$ / \mathrm{kWh})$, and charger price $(1000 \$ / \mathrm{kW})$ [3], the maximum power $P_{b}^{\max }$ maintains constant, equals to $2.26 \mathrm{~kW}$. The reason for this result may be due to the constraint of Eqn (2), not permitting power supply to the grid. The optimal values of battery energy capacity $Q_{b, e a p}$ are shown in Fig. 34(a). The battery energy capacity is augmented as the optimization time horizon increases. The total electric costs with/without home BESS for different time horizons of optimization are also shown in Fig. 3.(b).

Given the battery price and charger price of $100 \$ / \mathrm{kWh}$ and $1000 \$ / \mathrm{kW}$, as well as different time horizons, the optimal values of home battery energy 


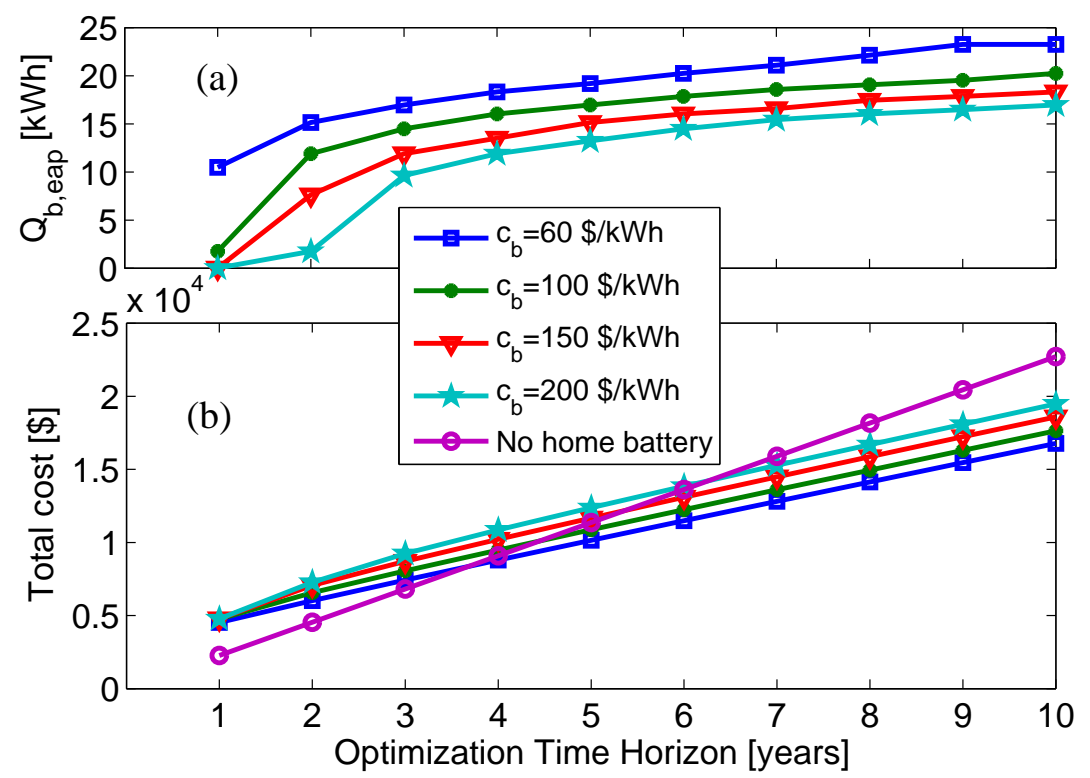

Figure 3: Battery energy capacity and total electric cost, given different time horizons and battery prices.

capacity $Q_{b, e a p}$, and electric cost are shown in Table 3 , where $F_{e}, F, F_{n o B}$, and $F_{\text {diff }}$ are the electric cost for one year with home BESS, the total cost with BESS in $n$ years, the electric cost without BESS, and the cost difference between the cases with and without BESS in $n$ years, respectively. The home battery energy capacity increases as the time horizon becomes larger. The total cost $F$ of the house with home BESS is larger than that in the case of the house without home BESS, when the time horizon is less than 5 years. However, when the time horizon is 5 years, the house with home BESS, for instance, can save $487 \$$. The cost savings become more significant with increased time horizons. If we assume a home battery life to be 5 years 44, the optimal value of home battery energy capacity that we consider is $17 \mathrm{kWh}$, and the cost of home BESS is $3960 \$$. With home BESS, the electric energy cost in one year is $1382 \$$, whereas without the BESS, the counterpart is $2271.3 \$$. The associated reduction reaches up to around $39.2 \%$. 


\subsection{Optimal results based on different types and control modes of PEV}

This subsection presents the resulting CP control law simulated on smart home with PEVs manufactured by different companies, including Nissan Leaf, Tesla Mode S, BYD E6, Chevrolet Volt, and Toyota Pruis. Here we assume that the time horizon of optimization is 6 years, and the home battery price and charger price are $100 \$ / \mathrm{kWh}$ and $1000 \$ / \mathrm{kW}$. Two control modes of PEV are considered, i.e., $\mathrm{H} 2 \mathrm{~V}$ and $\mathrm{V} 2 \mathrm{H}$ modes. In $\mathrm{H} 2 \mathrm{~V}$ mode, the PEV battery cannot supply power to the house, $0 \leq P_{e v c, k} \leq P_{e v c}^{\max }$. In V2H mode, the PEV battery can supply power to the house, $-P_{e v c}^{\max } \leq P_{e v c, k} \leq P_{e v c}^{\max }$ [45].

Considering different types of PEVs (with different battery energy capacities and chargers), the optimal parameters of home BESS $Q_{b, e a p}$ and $P_{b, \max }$, and the total cost are shown in Table 4. In $\mathrm{H} 2 \mathrm{~V}$ mode and $\mathrm{V} 2 \mathrm{H}$ mode, independently of the types of PEVs, the maximum power $P_{b, \max }$ keeps constant, equal to 2.26 $\mathrm{kW}$. In $\mathrm{H} 2 \mathrm{~V}$ mode, the optimal value of home battery energy capacity $Q_{b, e a p}$ is not affected by the EV battery energy capacity. In $\mathrm{V} 2 \mathrm{H}$ mode, the optimal values of home battery energy capacity $Q_{b, e a p}$ is affected by the EV battery energy capacity, but the influence is very small, i.e., $15.8 \mathrm{kWh} \leq Q_{b, \text { eap }} \leq 16.7$ $\mathrm{kWh}$

With/without home BESS, the total cost in V2H mode is less than that in $\mathrm{H} 2 \mathrm{~V}$ mode. For the same type PEV with the same control mode, the total cost with home BESS is less than that without home BESS.

\subsection{Example of energy management strategy}

This subsection presents the resulting CP control law in a smart home with a Nissan Leaf, simulated on two different operating modes, including H2V mode and $\mathrm{V} 2 \mathrm{H}$ mode. The hourly power allocation over two days is described in Fig. 4 . including the hourly home power demand $\left(P_{d e m}\right)$, the PV power generation $\left(P_{P V}\right)$, the home battery power $\left(P_{b}\right)$, the PEV battery power $\left(P_{e v c}\right)$, and the electric power from the grid $\left(P_{\text {grid }}\right)$. In both $\mathrm{H} 2 \mathrm{~V}$ and $\mathrm{V} 2 \mathrm{H}$ modes, it is evident that the majority of the home battery charging occurs during the low electricity price period: 24:00-7:00 and high PV power supply period: 10:00-15:00. Most of 

peak periods of electric price.

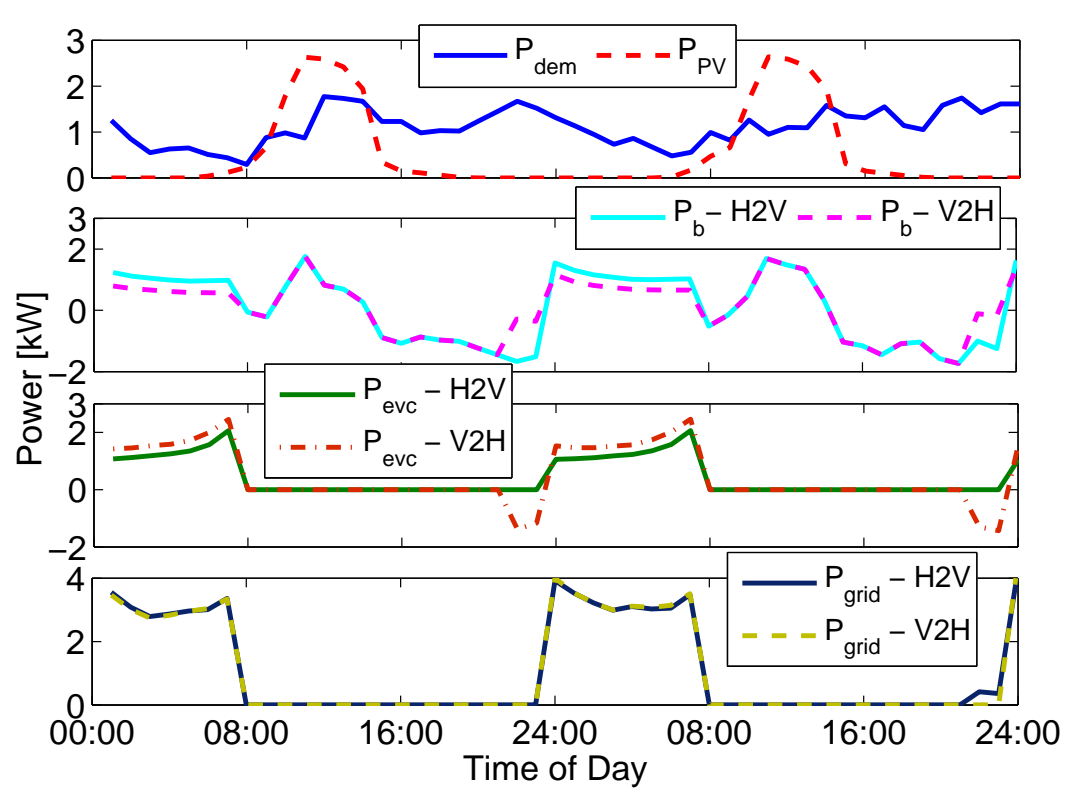

Figure 4: CP-optimized power allocation in two-day simulation.

the home battery discharging happens during the high electricity price period: 14:00-23:00. The majority of the PEV battery charging occurs during the low electricity price period: 23:00-7:00. In V2H mode, the PEV discharging power to the house appears during the high electricity price period and large home power demand: 21:00-23:00. The electric power from the grid is zero during the period: 8:00-23:00 in V2H mode. The electric power from the grid is zero during the period: 8:00-21:00 in H2V mode. In summary, in both H2V and $\mathrm{V} 2 \mathrm{H}$ modes, the home does not buy electric energy from the grid during the

In $\mathrm{H} 2 \mathrm{~V}$ and $\mathrm{V} 2 \mathrm{H}$ modes, energy trajectories of both home and PEV batteries are illustrated in Fig. 5. The home battery energy in H2V mode is always higher than that in the V2H mode. When the PEV plugs-in, the PEV battery energy in $\mathrm{H} 2 \mathrm{~V}$ mode is higher than that in the $\mathrm{V} 2 \mathrm{H}$ mode. In the course of PEV pluggingout, the PEV battery energy always equal to $S O C_{e v}^{\max } Q_{e v, e a p}$, because of the constraints Equ.(6). 


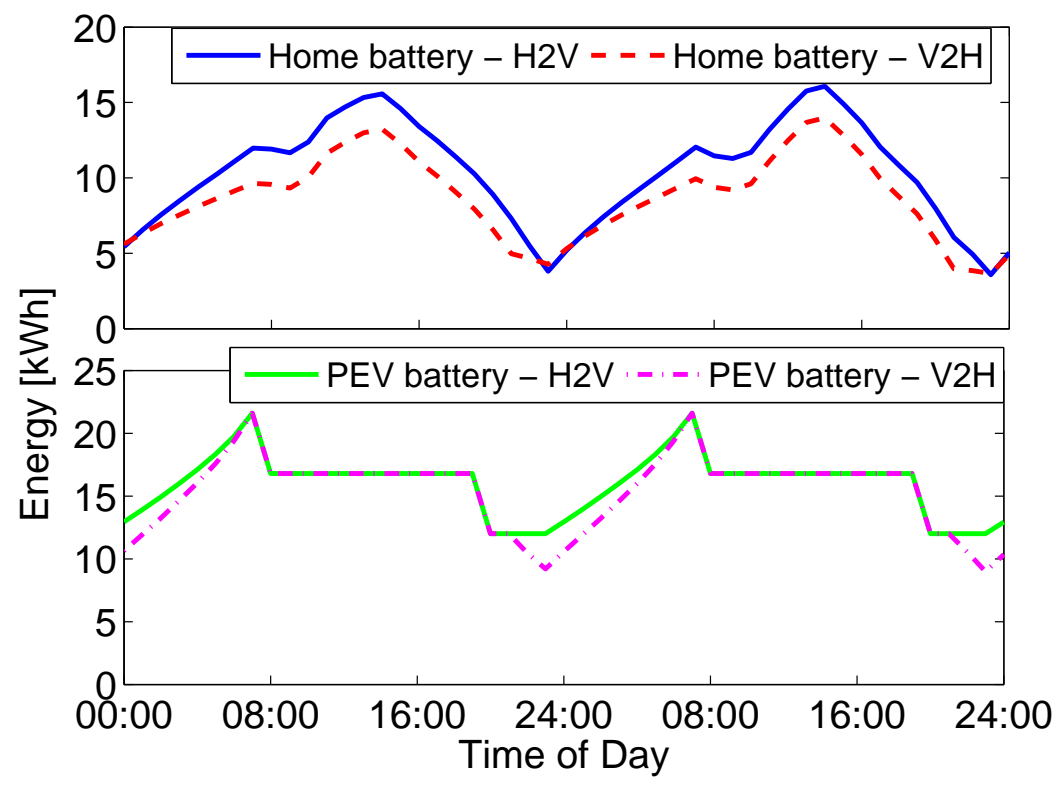

Figure 5: CP-optimized battery energy trajectory in two-day simulation.

To demonstrate the potential economic benefits of the smart home nanogrid, we analyse the electric energy cost in a comparative fashion. The hourly electric energy cost for two days are shown in Fig. 6, including the cost of home power demand, the earned money of PV generation, the earned money of home battery, the cost of PEV battery charging, and the total electric cost. The two-day electric energy cost of home power demand is $13.90 \$$, and the two-day earned money of PV generation is $6.02 \$$. The two-day earned money of home battery is $4.62 \$$ in $\mathrm{H} 2 \mathrm{~V}$ mode and $4.22 \$$ in $\mathrm{V} 2 \mathrm{H}$ mode. The two-day cost of PEV battery charging is $2.13 \$$ in $\mathrm{H} 2 \mathrm{~V}$ mode and $1.59 \$$ in $\mathrm{V} 2 \mathrm{H}$ mode. The two-day total electricity cost is $5.39 \$$ in $\mathrm{H} 2 \mathrm{~V}$ mode and $5.25 \$$ in $\mathrm{V} 2 \mathrm{H}$ mode. Therefore, the total electric cost in $\mathrm{V} 2 \mathrm{H}$ mode is $2.6 \%$ lower than that in $\mathrm{H} 2 \mathrm{~V}$ mode.

\section{Conclusions}

This paper develops a CP framework for optimal energy management and component sizing of a hybrid solar-battery power source for smart home nanogrid 


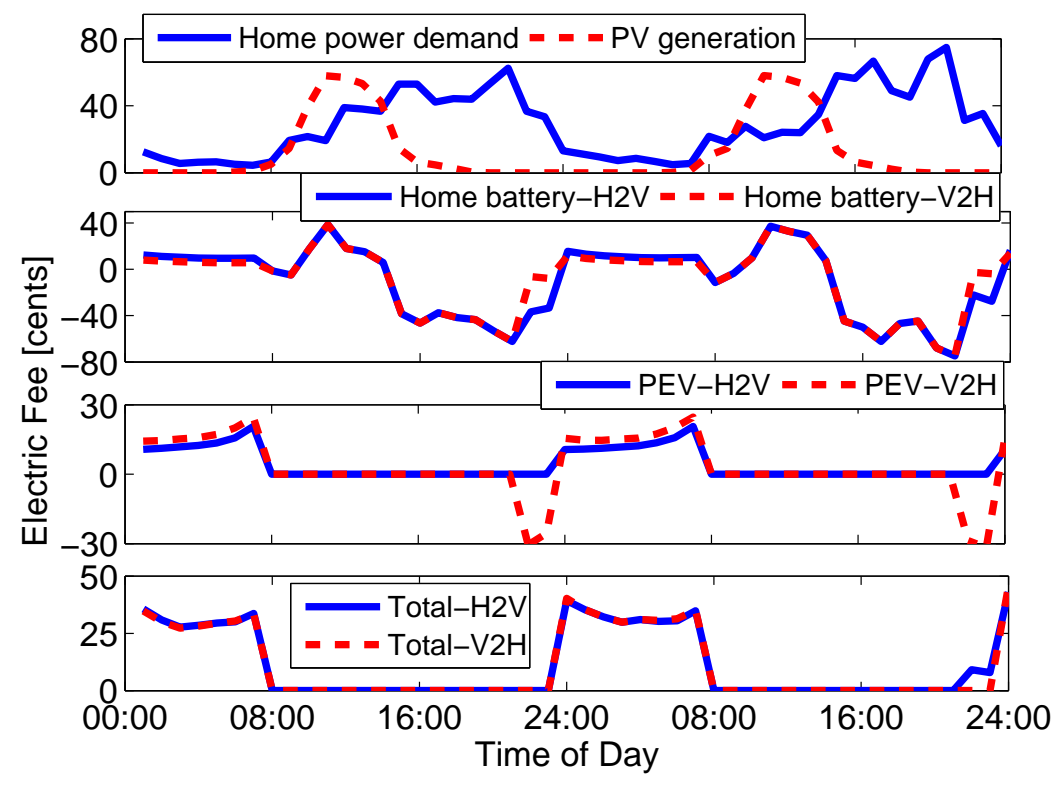

Figure 6: CP-optimized electric energy cost in two-day simulation.

with PEV load. The CP problem is mathematically formulated to optimize the electric power allocation among the PEV battery, home battery, home power demand, PV arrays, and utility grid. At the same time, the CP strategy explicitly takes into account the optimization of home BESS's parameters. Different time horizons of optimization, home battery prices, types and control modes of PEVs are also considered in extensive simulation campaigns.

Results substantiate that the developed CP method can efficiently solve the optimization problem, and the home BESS, accounting for a suitable time horizon of optimization, contributes to significant operational cost savings, in contrast to the option without home BESS. Further, it is found that the total electric cost in $\mathrm{V} 2 \mathrm{H}$ mode (with bidirectional PEV-to-home/home-to-PEV power flow) is $2.6 \%$ lower than that in $\mathrm{H} 2 \mathrm{~V}$ mode (with unidirectional hometo-PEV power flow).

The future work could incorporate more likely uncertainties into the optimization framework, regarding the house power demand, time-varying elec- 
tricity price, renewable power generation, the plug-in/plug-out state of PEV, etc.

\section{References}

[1] S. Habib, M. Kamran, U. Rashid, Impact analysis of vehicle-to-grid technology and charging strategies of electric vehicles on distribution networks - a review, Journal of Power Sources 277 (2015) 205 - 214.

[2] L. Zhang, F. Jabbari, T. Brown, S. Samuelsen, Coordinating plug-in electric vehicle charging with electric grid: Valley filling and target load following, Journal of Power Sources 267 (2014) 584 - 597.

[3] B. Tarroja, J. D. Eichman, L. Zhang, T. M. Brown, S. Samuelsen, The effectiveness of plug-in hybrid electric vehicles and renewable power in support of holistic environmental goals: Part 2 - design and operation implications for load-balancing resources on the electric grid, Journal of Power Sources 278 (2015) $782-793$.

[4] B. Tarroja, J. D. Eichman, L. Zhang, T. M. Brown, S. Samuelsen, The effectiveness of plug-in hybrid electric vehicles and renewable power in support of holistic environmental goals: Part 1 - evaluation of aggregate energy and greenhouse gas performance, Journal of Power Sources 257 (2014) 461 -470 .

[5] P. D. Lund, J. Lindgren, J. Mikkola, J. Salpakari, Review of energy system flexibility measures to enable high levels of variable renewable electricity, Renewable and Sustainable Energy Reviews 45 (0) (2015) 785 - 807.

[6] F. Bella, A. Lamberti, S. Bianco, E. Tresso, C. Gerbaldi, C. F. Pirri, Floating, flexible polymeric dye-sensitized solar-cell architecture: The way of near-future photovoltaics, Advanced Materials Technologies 1 (2) (2016) 1 $-9$. 
[7] F. Bella, G. Leftheriotis, G. Griffini, G. Syrrokostas, S. Turri, M. Gratzel, C. Gerbaldi, A new design paradigm for smart windows: Photocurable polymers for quasi-solid photoelectrochromic devices with excellent longterm stability under real outdoor operating conditions, Advanced Functional Materials 26 (7) (2016) 1127 - 1137.

[8] A. Scalia, F. Bella, A. Lamberti, S. Bianco, C. Gerbaldi, E. Tresso, C. F. Pirri, A flexible and portable powerpack by solid-state supercapacitor and dye-sensitized solar cell integration, Journal of Power Sources 359 (2017) $311-321$.

[9] S. Tong, T. Fung, M. P. Klein, D. A. Weisbach, J. W. Park, Demonstration of reusing electric vehicle battery for solar energy storage and demand side management, Journal of Energy Storage 11 (2017) 200 - 210.

[10] F. De Angelis, M. Boaro, D. Fuselli, S. Squartini, F. Piazza, Q. Wei, Optimal home energy management under dynamic electrical and thermal constraints, IEEE Transactions on Industrial Informatics 9 (3) (2013) 1518 1527.

[11] G. Wang, Q. Zhang, H. Li, B. C. McLellan, S. Chen, Y. Li, Y. Tian, Study on the promotion impact of demand response on distributed pv penetration by using non-cooperative game theoretical analysis, Applied Energy 185, Part 2 (2017) $1869-1878$.

[12] C. Sun, F. Sun, S. J. Moura, Nonlinear predictive energy management of residential buildings with photovoltaics \& batteries, Journal of Power Sources 325 (2016) $723-731$.

[13] M. Muratori, G. Rizzoni, Residential demand response: Dynamic energy management and time-varying electricity pricing, IEEE Transactions on Power Systems 31 (2) (2016) 1108 - 1117.

[14] J. Munkhammar, J. Widn, J. Rydn, On a probability distribution model 
combining household power consumption, electric vehicle home-charging and photovoltaic power production, Applied Energy 142 (2015) 135 - 143.

[15] O. Erdinc, Economic impacts of small-scale own generating and storage units, and electric vehicles under different demand response strategies for smart households, Applied Energy 126 (2014) 142 - 150.

[16] O. Erdinc, N. G. Paterakis, T. D. P. Mendes, A. G. Bakirtzis, J. P. S. Catalao, Smart household operation considering bi-directional ev and ess utilization by real-time pricing-based dr, IEEE Transactions on Smart Grid 6 (3) (2015) $1281-1291$.

[17] N. G. Paterakis, O. Erdinc, A. G. Bakirtzis, J. P. S. Catalao, Optimal household appliances scheduling under day-ahead pricing and load-shaping demand response strategies, IEEE Transactions on Industrial Informatics 11 (6) (2015) $1509-1519$.

[18] N. G. Paterakis, O. Erdinc, I. N. Pappi, A. G. Bakirtzis, J. P. S. Catalao, Coordinated operation of a neighborhood of smart households comprising electric vehicles, energy storage and distributed generation, IEEE Transactions on Smart Grid PP (99) (2016) 1 - 12.

[19] N. G. Paterakis, A. Tascikaraoglu, O. Erdinc, A. G. Bakirtzis, J. P. S. Catalao, Assessment of demand-response-driven load pattern elasticity using a combined approach for smart households, IEEE Transactions on Industrial Informatics 12 (4) (2016) 1529 - 1539.

[20] O. Erdinc, A. Tascikaraoglu, N. G. Paterakis, Y. Eren, J. P. S. Catalao, End-user comfort oriented day-ahead planning for responsive residential hvac demand aggregation considering weather forecasts, IEEE Transactions on Smart Grid 8 (1) (2017) 362 - 372.

[21] O. Erdinc, N. G. Paterakis, I. N. Pappi, A. G. Bakirtzis, J. P. Catalao, A new perspective for sizing of distributed generation and energy storage for 
smart households under demand response, Applied Energy 143 (2015) 26 37.

[22] Y. Wang, X. Lin, M. Pedram, A near-optimal model-based control algorithm for households equipped with residential photovoltaic power generation and energy storage systems, IEEE Transactions on Sustainable Energy 7 (1) (2016) $77-86$.

[23] T. C. Chiu, Y. Y. Shih, A. C. Pang, C. W. Pai, Optimized day-ahead pricing with renewable energy demand-side management for smart grids, IEEE Internet of Things Journal 4 (2) (2017) $374-383$.

[24] T. Wang, H. Kamath, S. Willard, Control and optimization of grid-tied photovoltaic storage systems using model predictive control, IEEE Transactions on Smart Grid 5 (2) (2014) 1010 - 1017.

[25] A. Nagarajan, R. Ayyanar, Design and strategy for the deployment of energy storage systems in a distribution feeder with penetration of renewable resources, IEEE Transactions on Sustainable Energy 6 (3) (2015) 1085 1092 .

[26] Z. Wang, R. Paranjape, Optimal residential demand response for multiple heterogeneous homes with real-time price prediction in a multiagent framework, IEEE Transactions on Smart Grid 8 (3) (2017) 1173 - 1184.

[27] H. Nafisi, S. M. M. Agah, H. A. Abyaneh, M. Abedi, Two-stage optimization method for energy loss minimization in microgrid based on smart power management scheme of phevs, IEEE Transactions on Smart Grid 7 (3) (2016) $1268-1276$.

[28] K. M. Tsui, S. C. Chan, Demand response optimization for smart home scheduling under real-time pricing, IEEE Transactions on Smart Grid 3 (4) (2012) $1812-1821$. 
[29] Y. Wang, X. Lin, M. Pedram, Adaptive control for energy storage systems in households with photovoltaic modules, IEEE Transactions on Smart Grid 5 (2) (2014) $992-1001$.

[30] X. Hu, Y. Zou, Y. Yang, Greener plug-in hybrid electric vehicles incorporating renewable energy and rapid system optimization, Energy 111 (2016) $971-980$.

[31] X. Hu, N. Murgovski, L. Johannesson, B. Egardt, Optimal dimensioning and power management of a fuel cell/battery hybrid bus via convex programming, IEEE/ASME Transactions on Mechatronics 20 (1) (2015) 457 -468 .

[32] N. Murgovski, L. Johannesson, J. Sjberg, B. Egardt, Component sizing of a plug-in hybrid electric powertrain via convex optimization, Mechatronics $22(1)(2012) 106-120$.

[33] S. Marinkov, N. Murgovski, B. de Jager, Convex modeling and sizing of electrically supercharged internal combustion engine powertrain, IEEE Transactions on Vehicular Technology 65 (6) (2016) 4523 - 4534.

[34] X. Wu, X. Hu, S. Moura, X. Yin, V. Pickert, Stochastic control of smart home energy management with plug-in electric vehicle battery energy storage and photovoltaic array, Journal of Power Sources 333 (2016) 203 212.

[35] X. Wu, X. Hu, X. Yin, S. Moura, Stochastic optimal energy management of smart home with pev energy storage, IEEE Transactions on Smart Grid PP (99) (2017) 1-1.

[36] A. Purvins, M. Sumner, Optimal management of stationary lithium-ion battery system in electricity distribution grids, Journal of Power Sources 242 (2013) $742-755$. 
[37] USDOT-FHWA, National household travel survey, Tech. rep., U.S. Department of Transportation, Federal Highway Administration, http://nhts.ornl.gov/index.shtml (2009).

[38] S. Boyd, L. Vandenberghe, Convex Optimization, Cambrige, U.K.: Cabridge Univ. Press, 2004.

[39] J. F. Sturm, Using sedumi 1.02, a matlab toolbox for optimization over symmetric cones, Optimization Methods and Software 11 (1-4) (1999) 625 $-653$.

[40] SolarCity, Solarcity, Tech. rep., SolarCity, http://www.solarcity.com/ (2014).

[41] P. Gas, E. Company, Electric vehicles making sense of the rates, Tech. rep., Pacific Gas and Electric Company, http://www.pge.com/en/myhome/saveenergymoney/pev/rates/index.page $(2015)$.

[42] C. Pillot, The worldwide battery market 2012-2025, Tech. rep., Avicenne Energy (2013).

[43] M. Yilmaz, P. T. Krein, Review of battery charger topologies, charging power levels, and infrastructure for plug-in electric and hybrid vehicles, IEEE Transactions on Power Electronics 28 (5) (2013) 2151 - 2169.

[44] Calculate the cost of photovoltaic systems home solar electricity, Tech. rep., New Mexico Solar Energy Association (2015).

[45] D. Wu, H. Zeng, C. Lu, B. Bouletu, Two-stage energy management for office buildings with workplace ev charging and renewable energy, IEEE Transactions on Transportation Electrification 3 (1) (2017) 225 - 237. 
Table 1: Nomenclature

\begin{tabular}{|c|c|}
\hline$c_{b}$ & home battery price per kiloWatt-hour $[\$ / \mathrm{kWh}]$ \\
\hline$c_{c}$ & charger price per kiloWatt $[\$ / \mathrm{kW}]$ \\
\hline$c_{e, k}$ & electricity price $[$ cents $/ \mathrm{kWh}]$ \\
\hline$C_{n y}$ & $n$-year total electricity cost $[\$]$ \\
\hline$E_{e v, k}$ & energy of PEV battery $[\mathrm{kWh}]$ \\
\hline$E_{e v, i n i t}$ & initial PEV battery energy $[\mathrm{kWh}]$ \\
\hline$E_{e v}^{p l u g-o u t}$ & energy of PEV battery when the vehicle plugging-out [kWh] \\
\hline$E_{e v}^{p l u g-i n}$ & energy of PEV battery when the vehicle plugging-in [kWh] \\
\hline$E_{d r}$ & consumed energy for driving in a whole day $[\mathrm{kWh}]$ \\
\hline$E_{b, k}$ & energy of home battery $[\mathrm{kWh}]$ \\
\hline$E_{b, i n i t}$ & initial home battery energy $[\mathrm{kWh}]$ \\
\hline$k$ & time index \\
\hline$N$ & final time step of one year \\
\hline$n$ & time horizon of optimization [year] \\
\hline$P_{\text {grid }, k}$ & electric power from the grid $[\mathrm{kW}]$ \\
\hline$P_{d e m, k}$ & electric load demand of the house $[\mathrm{kW}]$ \\
\hline$P_{b, k}$ & electric power of home battery $[\mathrm{kW}]$ \\
\hline$P_{e v c, k}$ & electric power of PEV battery $[\mathrm{kW}]$ \\
\hline$P_{p v, k}$ & power supply of PV arrays $[\mathrm{kW}]$ \\
\hline$P_{\text {grid }}^{\max }$ & maximal power from the grid $[\mathrm{kW}]$ \\
\hline$P_{e v c}^{\min }$ & PEV battery's minimal power $[\mathrm{kW}]$ \\
\hline$P_{e v c}^{\max }$ & PEV battery's maximal power $[\mathrm{kW}]$ \\
\hline$P_{b}^{\max }$ & home battery's maximal power $[\mathrm{kW}]$ \\
\hline$Q_{e v c, e a p}$ & energy capacity of the PEV battery [kWh] \\
\hline$Q_{b, e a p}$ & energy capacity of the home battery $[\mathrm{kWh}]$ \\
\hline$S_{k}$ & PEV state at time $k$ \\
\hline$t_{d}$ & plugging-out time \\
\hline$t_{a}$ & plugging-in time \\
\hline$S O C_{e v}^{\min }$ & PEV battery's minimal SOC \\
\hline$S O C_{e v}^{\max }$ & PEV battery's maximal SOC \\
\hline$S O C_{b}^{\min }$ & home battery's minima\$3SOC \\
\hline$S O C_{b}^{\max }$ & home battery's maximal SOC \\
\hline$\Delta t$ & time-step $[\mathrm{h}]$ \\
\hline$\eta_{e v c}$ & lost efficiency of PEV battery \\
\hline$\eta_{b}$ & lost efficiency of home battery \\
\hline
\end{tabular}


Table 2: Key parameters.

\begin{tabular}{llll}
\hline \hline Parameter Description & Symbol & Value & Unit \\
\hline Step time & $\Delta t$ & 1 & hour \\
Maximum PEV battery SOC & $S O C_{e v}^{\max }$ & 0.90 & - \\
Minimum PEV battery SOC & $S O C_{e v}^{\min }$ & 0.20 & - \\
Maximum home battery SOC & $S O C_{b}^{\max }$ & 0.90 & - \\
Minimum home battery SOC & $S O C_{b}^{\min }$ & 0.20 & - \\
PEV plugging-out time & $t_{d}$ & $7: 00 \mathrm{AM}$ & - \\
PEV plugging-in time & $t_{a}$ & $8: 00 \mathrm{PM}$ & - \\
Lost efficiency & $\eta_{e v c} / \eta_{b}$ & 0.10 & \\
Maximum power from grid & $P_{g r i d}^{\max }$ & 10 & $\mathrm{~kW}$ \\
\hline \hline
\end{tabular}

Table 3: Optimal value $\left(c_{b}=100 \$ / \mathrm{kWh}\right.$ and $\left.c_{c}=1000 \$ / \mathrm{kW}\right)$.

\begin{tabular}{llllll}
\hline \hline$n /$ year & $Q_{b, \text { eap }} / \mathrm{kWh}$ & $F_{e} / \$$ & $F / \$$ & $F_{\text {noB }} / \$$ & $F_{\text {diff }} / \$$ \\
\hline 1 & 1.75 & 2330.9 & 4765.8 & 2271.3 & 2494.5 \\
2 & 11.90 & 1554.6 & 6558.7 & 4542.7 & 2016 \\
3 & 14.49 & 1448.8 & 8055.1 & 6814.0 & 1241.1 \\
4 & 16.03 & 1403.6 & 9477.2 & 9085.4 & 391.8 \\
5 & 16.97 & 1382.0 & 10870 & 11357 & -487 \\
6 & 17.85 & 1366.2 & 12243 & 13682 & -1439 \\
7 & 18.56 & 1355.3 & 13603 & 15899 & -2296 \\
8 & 19.06 & 1348.5 & 14954 & 18171 & -3217 \\
9 & 19.53 & 1343.0 & 16300 & 20442 & -4142 \\
10 & 20.25 & 1335.5 & 17640 & 22713 & -5073 \\
\hline \hline
\end{tabular}


Table 4: Optimal values of home battery energy capacity for different types of PEVs.

\begin{tabular}{llllll}
\hline \hline & Leaf & Mode S & E6 & Volt & Pruis \\
\hline$Q_{\text {evc,eap }}(\mathrm{kWh})$ & 24 & 85 & 82 & 16 & 5.2 \\
$P_{\text {evc }}^{\max }(\mathrm{kW})$ & 3.6 & 10 & 10 & 3.6 & 3.6 \\
$Q_{b, \text { eap }}$ in H2V mode $(\mathrm{kWh})$ & 17.85 & 17.85 & 17.85 & 17.85 & 17.85 \\
$Q_{b, \text { eap }}$ in V2H mode $(\mathrm{kWh})$ & 15.9 & 15.84 & 15.84 & 15.98 & 16.69 \\
$P_{b, \text { max }}$ in H2V mode $(\mathrm{kW})$ & 2.26 & 2.26 & 2.26 & 2.26 & 2.26 \\
$P_{b, \text { max }}$ in V2H mode $(\mathrm{kW})$ & 2.26 & 2.26 & 2.26 & 2.26 & 2.26 \\
Total cost with BESS $-\mathrm{H} 2 \mathrm{~V}(\$)$ & 12243 & 18188 & 17896 & 11463 & 10410 \\
Total cost with BESS $-\mathrm{V} 2 \mathrm{H}(\$)$ & 11827 & 17770 & 17478 & 11091 & 10250 \\
Total cost without BESS $-\mathrm{H} 2 \mathrm{~V}(\$)$ & 13628 & 19574 & 19281 & 12848 & 11796 \\
Total cost without BESS - V2H $(\$)$ & 12919 & 18843 & 18550 & 12193 & 11517 \\
\hline \hline
\end{tabular}


2017-08-01

\section{Optimal integration of a hybrid} solar-battery power source into smart home nanogrid with plug-in electric vehicle

Wu, Xiaohua

Elsevier

Wu X, Hu X, Teng Y, Qian S, Cheng R, Optimal integration of a hybrid solar-battery power source into smart home nanogrid with plug-in electric vehicle, Journal of Power Sources, Vol. 363, 30 September 2017, pp. 277-283 http://dx.doi.org/10.1016/j.jpowsour.2017.07.086 Downloaded from Cranfield Library Services E-Repository 